\title{
Simultaneous characterization and quantification of phenolic compounds in Thymus $x$ citriodorus using a validated HPLC-UV and ESI-MS combined method
}

\author{
Olívia R. Pereira ${ }^{\mathrm{a}, \mathrm{b}, \mathrm{c}}$, António M. Peres ${ }^{\mathrm{c}, \mathrm{d}}$, Artur M.S. Silva ${ }^{\mathrm{e}}$, Maria R.M. Domingues ${ }^{\mathrm{e}}$, Susana M. Cardoso ${ }^{\mathrm{a}, \mathrm{c}, *}$ \\ a CERNAS, Escola Superior Agrária, Instituto Politécnico de Coimbra, Bencanta, 3040-316 Coimbra, Portugal \\ b DTDT, Escola Superior de Saúde, Instituto Politécnico de Bragança, Av. D. Afonso V, 5300-121 Bragança, Portugal \\ c CIMO, Escola Superior Agrária, Instituto Politécnico de Bragança, Campus de Santa Apolónia, 5301-854 Bragança, Portugal \\ d LSRE, Escola Superior Agrária, Instituto Politécnico de Bragança, Campus de Santa Apolónia, 5301-854 Bragança, Portugal \\ ' Departamento de Química E' QOPNA, Universidade de Aveiro, 3810-193 Aveiro, Portugal
}

\section{A R T I C L E I N F O}

\section{Article history:}

Received 24 June 2013

Accepted 15 September 2013

Available online 21 September 2013

\section{Keywords:}

Thymus $x$ citriodorus

Phenolic compounds

Flavonoids

Luteolin-7-O- $\alpha$-glucuronide

Rosmarinic acid

Mass spectrometry

Electrospray ionization

\begin{abstract}
A B S T R A C T
Thymus $x$ citriodorus is a Lamiaceae plant extensively cultivated in the Mediterranean region and used for centuries in culinary and in traditional medicine. The present work describes the detailed phenolic composition of T. $x$ citriodorus for the first time, by means of HPLC-DAD, ESI-MS and $\mathrm{MS}^{\mathrm{n}}$ and nuclear magnetic resonance (NMR) analyses. The ethanolic extract of T. $x$ citriodorus was analyzed by reversed phase HPLC. The method of analysis was also validated concerning its linearity, instrumental and method precision (for repeatability, immediate precision and intermediate precision) and accuracy (absolute recovery study). The technique was combined with electrospray mass spectrometry in order to identify the phenolic compounds and the structure of the main phenolics was also confirmed by NMR analysis. The in-house validated HPLC-DAD method showed good linearity for the tested reference compounds as well as satisfactory repeatability and immediate precision values, for both instrument and method. Furthermore, the satisfactory results of intermediate precision analysis and recovery assays indicated that the chromatographic method could be used to quantify the main phenolic compounds of $T$. $x$ citriodorus with adequate precision and accuracy. The extract was rich in rosmarinic acid $(10.4 \pm 0.6 \mathrm{mg} / \mathrm{g}$ extract) that is a widespread phenolic acid in Thymus plants, but also in luteolin-7-0- $\alpha$-glucuronide (12 $\pm 2 \mathrm{mg} / \mathrm{g}$ extract), that was herein reported in Thymus for the first time. Other novel compounds comprised one eriodictyol dihexoside with $O$-glycosidic linkages, two eriodictyol-O-monohexosides, one quercetagetin dimethyl ether- $O$-hexoside, one naringenin- $O$-hexoside and chrysoeriol-7- $\beta$ - $O$-glucoside. Having in mind the health-promoting properties reported in literature for some of the main polyphenols found in T. $x$ citriodorus, we suggest that this plant has a high potential for being used as a functional food.
\end{abstract}

(C) 2013 Elsevier Ltd. All rights reserved.

\section{Introduction}

In recent years, several industries have shown a great interest in edible plants and in their bioactive compounds because of their potential applications, including as functional food and nutraceuticals (Wijngaard, Hossain, Rai, \& Brunton, 2012). Thymus L. is a large genus belonging to the Lamiaceae family, which comprises 300-400 endemic species widely distributed in the entire World, in particular in the Mediterranean region. These plants are perennial, herbaceous, tender and of simple small leaves with ramified and prostrated branches, forming a shrub with uncountable branches, typically reaching a height of 10 to $30 \mathrm{~cm}$ (Reddy, Angers, Gosselin, \& Arul, 1998).

\footnotetext{
* Corresponding author at: CERNAS, Escola Superior Agrária, Instituto Politécnico de Coimbra, Bencanta, 3040-316 Coimbra, Portugal. Tel.: + 351239 802940; fax: + 351239 802979.

E-mail address: scardoso@esac.pt (S.M. Cardoso).
}

Many Thymus species are known as culinary herbs and have been cultivated for usage in the confection of several dishes and in flavoring salads, soups, stews and sauces. Additionally, Thymus species are used in infusion form as medicinal plants because of their biological and pharmacological properties, which include expectorant, antiasthmatic, bronchiolytic, anti-septic, antispasmodic, analgesic, antimicrobial, and antioxidant (Gião et al., 2007; Mata et al., 2007; Pinto et al., 2006). It is believed that some of these beneficial activities are due to their volatile constituents and thus, their essential oil composition has been the focus of many investigations (Horvath, Szabo, Hethelyi, \& Lemberkovics, 2006; Omidbaigi, Sefidkon, \& Hejazi, 2005). In contrast, there are only a limited number of studies focusing the composition of other bioactive phytochemicals of Thymus plants, such as their phenolic compounds. According to the few studies on this topic, the hydrophilic extracts of dried thyme plants contain caffeic acid and its oligomers [rosmarinic acid, 3'-O-(8"-caffeoyl) rosmarinic acid, lithospermic acid and methyl rosmarinate], flavones 
(apigenin, luteolin, luteolin-7-O- $\beta$-glucuronide, luteolin-7-O-glucoside, 6-hydroxyluteolin glycosides, chrysoeriol and polymethoxyflavones), flavanones (naringenin, naringenin-7-O-glucoside, narirutin, eriodictyol, eriodictyol-7-O-glucoside, isosakuranetin, eriocitrin and hesperidin), and the flavanol taxifolin (Dorman, Bachmayer, Kosar, \& Hiltunen, 2004; Fecka \& Turek, 2008).

Thymus $x$ citriodorus, or lemon thyme, is one of the most used Thymus in culinary (The Herb Society of America, 2003). The plant is used as an ingredient for confection of several recipes of starter (Cheese-stuffed Nasturtiums), snacks, sauces (Chili Oil, Soyer's Recipe for Goose Stuffing) and different meat (Meat Stuffing for Duck), fish (Fish Aspic Jelly) or vegetarian (Spinach Frittata with Herbs) dishes. Additionally, it is used in jellies and desserts (Lemon Thyme Jelly) for confection of soups (Cream of Porcini Soup, Thick Giblet Soup) and consumed in fresh salads as well as in marinades for grilled fish, chicken and roast duck, potatoes and carrots (Celtnet, 2013). Besides its culinary usage, T. $x$ citriodorus is also vastly consumed in the form of tea, for medicinal proposals.

Despite the widespread culinary consumption of T. $x$ citriodorus and its claimed health benefits, the detailed knowledge of its phenolic constituents remains unknown. The present work used a combination of HPLC with ESI-MS/MS ${ }^{\mathrm{n}}$ and nuclear magnetic resonance (NMR) analysis, in order to contribute for the knowledge of the phenolic constituents in T. $x$ citriodorus.

\section{Experimental}

\subsection{Plant material}

T. $x$ citriodorus plants were purchased from ERVITAL (Castro de Aire, Portugal) as a mixture of leaves and stems. The plants have been cultivated under an organic regime and the collected aerial parts were dried at $25-30{ }^{\circ} \mathrm{C}$ in a ventilated incubator for approximately 5 days.

\subsection{Solvents and reagents}

$n$-Hexane was purchased from Pronalab (Lisbon, Portugal), the analytical grade reagents formic acid and ethanol were obtained from Panreac (Barcelona, Spain), methanol and acetonitrile with HPLC purity were purchased from Lab-Scan (Lisbon, Portugal). Water was treated in a Milli-Q water purification system (TGI Pure Water Systems, USA). Eriodictyol-7-O-glucoside, luteolin-7-O-glucoside, naringenin-7-Oglucoside, apigenin-7-O-glucoside, chrysoeriol and rosmarinic acid were obtained from Extrasynthese (Genay Cedex, France).

\subsection{Extraction of phenolic compounds}

Aerial parts (leaves and stems) of $T$. citriodorus ( $5 \mathrm{~g}$ ) were grounded and defatted three times with $150 \mathrm{~mL} n$-hexane, for $30 \mathrm{~min}$ each at room temperature. The residue was extracted with $150 \mathrm{~mL}$ of an $80 \%$ ethanol solution $(\mathrm{v} / \mathrm{v})$ at room temperature, for $30 \mathrm{~min}$. The resulting mixture was filtered and the residue was re-extracted in the same conditions for four times. At the end, the filtrated solutions were combined, concentrated, frozen at $-20{ }^{\circ} \mathrm{C}$ and freeze-dried. The dried extract was stored in vacuum desiccator at dark for subsequent use. Each sample was prepared in triplicate.

\subsection{HPLC-DAD analyses}

\subsubsection{HPLC apparatus and chromatographic conditions}

The HPLC analysis was performed on a Varian 9010 separation module equipped with PDA Varian Prostar detector, under the general conditions previously described, with some modifications (Pereira, Silva, Domingues, \& Cardoso, 2012). Data acquisition and remote control of the HPLC system were done by Varian Star chromatography Workstation ${ }^{\circledR}$ (Lake Forest, CA, USA) software. The column was a
$250 \mathrm{~mm} \times 4 \mathrm{~mm}$ id, $5 \mu \mathrm{m}$ bead diameter, end-capped Nucleosil C18 (Macherey-Nagel) and its temperature was maintained at $30{ }^{\circ} \mathrm{C}$.

Gradient elution was carried out with a mixture of two solvents. Solvent A consisted of $0.1 \%(\mathrm{v} / \mathrm{v})$ of formic acid in water and solvent B consisted of acetonitrile, which were degassed and filtrated, using a $0.2 \mu \mathrm{m}$ nylon filter (Whatman, USA) before use. The solvent gradient consisted in a series of linear gradients: from 10 to $30 \%$ of solvent B over $20 \mathrm{~min}$, from 30 to $100 \%$ of solvent B over $5 \mathrm{~min}$, decreasing to $10 \%$ of solvent B after 5 min followed by the return to the initial conditions. The flow rate was $1 \mathrm{~mL} / \mathrm{min}$ and the injected volume was equal to $10 \mu \mathrm{L}$.

\subsubsection{Method in-house validation}

The HPLC method used to detect and quantify the phenolic compounds was validated for linearity, precision (assays performed for repeatability and intermediate precision) and accuracy (absolute recovery study).

2.4.2.1. Linearity, limits of detection and of quantification. An external standard calibration methodology was applied. Five solutions with different concentrations of eriodictyol-7-O-glucoside (10.0-135.9 $\mu \mathrm{g} / \mathrm{mL})$, naringenin-7-O-glucoside $(5.0-67.9 \mu \mathrm{g} / \mathrm{mL})$, luteolin-7-O-glucoside (45.3-300.0 $\mu \mathrm{g} / \mathrm{mL})$, apigenin-7-O-glucoside $(2.5-160.0 \mu \mathrm{g} / \mathrm{mL})$ and rosmarinic acid (14.9-120.0 $\mu \mathrm{g} / \mathrm{mL}$ ) were prepared by consecutive dilutions from a stock solution. The analyses were performed in triplicate and the results were plotted for evaluating the linear relationship between the peak areas of each phenolic standard. ANOVA was used to assess the statistical significance of each linear regression model being the quality of the fitted models evaluated by their $\mathrm{R}^{2}$ values. The statistical significances of the slope and of the intercept values were evaluated by a t-test. Finally, the regression data were subjected to a likelihood ratio test of equality (covariance analysis) to infer about inter-day variability of the calibration curves in order to avoid establishing a new calibration curve whenever a quantification procedure was needed. Statistic analyses were performed using the SPSS 17 Standard Version software (SPSS INC.) at a 5\% significance level. Detection (LOD) and quantification (LOQ) limits were calculated using the parameters of the calibration curves, being defined as 3.3 and 10 times the value of the regression error divided by the slope, respectively (Ermer \& Miller, 2005; Snyder, Kirkland, \& Dolan, 2010).

2.4.2.2. Precision (repeatability and intermediate precision). Both instrumental and method precisions were evaluated to verify the repeatability of the system and of the proposed method (extraction procedure followed by chromatographic analysis).

The instrumental system precision was studied using three standard solutions, containing eriodictyol-7-O-glucoside $(10,30$ or $80 \mu \mathrm{g} / \mathrm{mL})$, naringenin-7-O-glucoside $(5,40$ or $50 \mu \mathrm{g} / \mathrm{mL}$ ), luteolin-7-O-glucoside $(45,100$ or $300 \mu \mathrm{g} / \mathrm{mL})$, apigenin-7-0-glucoside $(10,80$ or $160 \mu \mathrm{g} / \mathrm{mL})$, and rosmarinic acid $(15,30$ or $150 \mu \mathrm{g} / \mathrm{mL})$, which corresponded to low, middle and high concentration levels. Each solution was injected, under the working conditions, 5 times on the same day to evaluate the repeatability of the instrumental system (i.e., intra-day variation, considering only within day variations). Further, the immediate precision of the system was evaluated by determining the variability of the responses of the injections of the three standard solutions, injected 3 times per day in three consecutive days (i.e., inter-day variation, considering within and between day variations). The instrumental precision was assessed by calculating the relative standard deviation percentage (\%RSD).

The method precision was inferred based on the evaluation of repeatability and immediate precision. For that, an ethanolic extract from T. $x$ citriodorus was obtained according to the work conditions, from a sample of $T$. $x$ citriodorus $(5.0010 \pm 0.0001 \mathrm{~g})$ resulting in $0.75 \mathrm{~g}$ of lyophilized extract. Part of the lyophilized extract (50.6 mg) 
was re-dissolved into $5 \mathrm{~mL}$ of methanol and then injected 5 times in the same day and 3 times per day in three consecutive days for method repeatability and immediate precision assessment, respectively.

The intermediate precision of the method was studied using two extracts obtained from the same plant according to the procedure previously described (extracted, stirred, filtered, re-extracted, combined, concentrated under reduced pressure, frozen and finally freeze-dried separately). Each extract was injected in triplicate in three consecutive days. Subsequently, the intermediate precision of the method was evaluated by calculating the \%RSD value of each phenolic compound detected, considering within and between day variations as well as between extraction variations.

2.4.2.3. Accuracy. The accuracy of the proposed method was studied by evaluating the absolute recovery, which studies the retrieval of standards added to a biological sample, that was subjected to all steps of the extraction procedure (extraction, filtration, re-extraction, concentration and freeze-dried). Two levels of luteolin-7-O-glucoside and rosmarinic acid (the available phenolic standards corresponding to natural phenolic constituents of the T. $\mathbf{x}$ citriodorus) were added to $2.04 \pm$ $0.02 \mathrm{~g}$ of $T$. $\mathbf{x}$ citriodorus dry plant samples. The quantity of each substance recovered in relation to the added amount was calculated, taking into account the yield of the extraction procedure.

\subsubsection{Identification and quantification of the phenolic compounds}

The identification of the phenolic compounds of the ethanolic extracts of T. $x$ citriodorus was based on the UV-vis spectrum of the HPLC fractions together with their analysis by electrospray ionization mass spectrometry (ESI-MS and ESI-MS ${ }^{\mathrm{n}}$ ). This latter was performed on a Linear Ion trap LXQ mass spectrometer (ThermoFinnigan, San Jose, CA, USA), following the procedure previously described (Pereira, Silva, et al., 2012).

When standards were available, the identification of the compounds was further confirmed by comparison of their HPLC-DAD retention time, UV-vis profile and ESI-MS ${ }^{\mathrm{n}}$ data to those of the phenolic standards. Moreover, the structure of some compounds (luteolin-5- $\beta-O$-glucoside, luteolin-7- $\alpha$ - $O$-glucuronide, chrysoeriol-7- $\beta-O$-glucoside, apigenin-7$\beta-O$-glucuronide and rosmarinic acid) was further confirmed by NMR analysis. The HPLC freeze-dried collected fractions (2-3 mg) were dissolved in DMSO- $\mathrm{d}_{6}$ and the ${ }^{1} \mathrm{H}$ spectra were recorded at $298 \mathrm{~K}$ on a Bruker Avance 500 spectrometer operating at $500.13 \mathrm{MHz}$. 2D NMR (heteronuclear single quantum coherence, using gradient pulses for selection i.e. $\left({ }^{1} \mathrm{H},{ }^{13} \mathrm{C}\right)$ gHSQC, heteronuclear multiple quantum coherence, using gradient pulses for selection i.e. gHMBC) spectra were acquired in the same experimental conditions as previously described (Pereira, Domingues, Silva, \& Cardoso, 2012). ${ }^{13} \mathrm{C}$ NMR chemical shift assignments were made from the projections of the heteronuclear HSQC and HMBC experiments.

The quantification of phenolic compounds was performed by peak integration using the HPLC-DAD external standard method, with the most close reference compound available to that of the major compound in each HPLC eluting peak. More concretely, fraction 1 (eriodictyol-di-Ohexoside) and fraction 3 (eriodictyol-O-hexoside) were quantified using eriodictyol-7-0-glucoside as the reference compound. The same reference compound was also used to quantify fraction 2 (eriodictyol$O$-hexoside and quercetagetin dimethyl ether $O$-hexoside) as, in accordance to the UV-vis and MS spectra, the eriodictyol-O-hexoside was the major phenolic compound of that fraction. In a similar approach, fractions 5 (naringenin-O-hexoside and eriodictyol-O-hexuronide) and 6 (luteolin-7- $\alpha$-O-glucuronide plus luteolin-7-0-glucoside) were quantified using naringenin-7-O-glucoside and luteolin-7-O-glucoside as reference, respectively. Fraction 4 (luteolin-5- $\beta-0$-glucoside) and fraction 8 (apigenin-7- $\beta-0$-glucuronide) were respectively quantified using luteolin-7-O-glucoside and apigenin-7-O-glucoside as reference, while rosmarinic acid was used as the reference for quantification of phenolic compounds in fractions 9 (rosmarinic acid) and 10 [(3'-O(8"-Z-caffeoyl)rosmarinic acid)]. Moreover, and according to the maximum UV absorption, the quantification of compounds eluting in fractions 1, 2, 3 and 5 was performed by HPLC-DAD at $280 \mathrm{~nm}$ while the compounds eluting in fractions 4, 6, 8, 9 and 10 were quantified at $340 \mathrm{~nm}$.

\section{Results and discussion}

3.1. Identification of the phenolic compounds of the ethanolic extract of T. $x$ citriodorus

Overall, the identified phenolic compounds of the ethanolic extract from $T$. $x$ citriodorus enclosed rosmarinic acid and another less common phenolic acids, as well as derivatives of common flavonoids, including the flavones luteolin, chrysoeriol and apigenin, the flavanones eriodictyol and naringenin, and the flavonol quercetagetin (Table 1 ). A description of the T. $x$ citriodorus phenolic composition and the comparison to that previously described for other Thymus plants, will be discussed below in detail.

Table 1

Identification of HPLC-eluting fractions by HPLC/DAD and ESI/MS from T. $x$ citriodorus.

\begin{tabular}{|c|c|c|c|c|c|}
\hline $\begin{array}{l}\text { Fraction } \\
\text { number }\end{array}$ & $\begin{array}{l}\mathrm{RT} \\
(\min )\end{array}$ & $\lambda_{\max }$ & {$[\mathrm{M}-\mathrm{H}]^{-}$} & Main ESI-MS ${ }^{\mathrm{n}}$ (abundance) & Compound \\
\hline \multirow[t]{2}{*}{1} & 4.3 & 283,327 & 611 & $\begin{array}{l}\operatorname{MS}^{2}[611]: 449(100), 287(15) ; \operatorname{MS}^{3}[449]: 287(100), 151(<1) ; \operatorname{MS}^{4}[287]: 269(2), 151(100) \\
\operatorname{MS}^{5}[151]: 107\end{array}$ & Eriodictyol-di-O-hexoside \\
\hline & & & 387 & $\operatorname{MS}^{2}[387]:$ 369(15), 225(5), 207(100), 163(10), 119(1); $\mathrm{MS}^{3}[207]: 163 ; \mathrm{MS}^{4}[163]: 109$ & 5'-Hydroxyjasmonic acid 5'-O-hexoside \\
\hline \multirow[t]{2}{*}{2} & 6.8 & 283,327 & 449 & $\operatorname{MS}^{2}[449]: 287 ; \operatorname{MS}^{3}[287]: 151 ; \operatorname{MS}^{4}[151]: 107$ & Eriodictyol-O-hexoside \\
\hline & & & 507 & $\begin{array}{l}\mathrm{MS}^{2}[507]: 489(20), 471(10), 345(35), 327(100), 315(5) ; \mathrm{MS}^{3}[327]: 312(100), 167(20) ; \mathrm{MS}^{3} \\
\text { [345]: 327(100), 315(15), 309(20), 287(5) }\end{array}$ & Quercetagetin dimethyl ether $O$-hexoside \\
\hline 3 & 7.3 & 283,327 & 449 & $\begin{array}{l}\mathrm{MS}^{2}[449]: \text { 287(100), 269(<1), 151(1); } \mathrm{MS}^{3}[287]: 269(4), 161(<1), 151(100), 125(4) \\
\text { 107(1); } \mathrm{MS}^{4}[151]: 107\end{array}$ & Eriodictyol-O-hexoside \\
\hline 4 & 8.6 & 248,342 & 447 & $\mathrm{MS}^{2}[447]:$ 285(100); $\mathrm{MS}^{3}[285]:$ 243(60), 241(100), 199(100), 175(50), 151(10) & Luteolin-5- $\beta-O$-glucoside \\
\hline \multirow[t]{2}{*}{5} & 9.1 & 283,340 & 433 & $\mathrm{MS}^{2}[433]: 271(100) ; \mathrm{MS}^{3}[271]: 227(1), 177(10), 151(100), 107(2)$ & Naringenin-O-hexoside \\
\hline & & 283,327 & 463 & $\operatorname{MS}^{2}[463]: 301(20), 287(100) ; \operatorname{MS}^{3}[287]: 151(100), 135(<1), 125(<1)$ & Eriodictyol-O-hexuronide \\
\hline \multirow[t]{2}{*}{6} & 9.6 & 254,267 & 461 & $\mathrm{MS}^{2}[461]: 285(100) ; \mathrm{MS}^{3}[285]: 241(95), 217(60), 199(60), 175(60), 151(20)$ & Luteolin-7- $\alpha$ - 0 -glucuronide \\
\hline & & 345 & 447 & $\mathrm{MS}^{2}[447]: 285 ; \mathrm{MS}^{3}[285]: 243(50), 241(100), 199(60), 175(50), 151(15)$ & Luteolin-7-O-glucoside \\
\hline 7 & 10.9 & 245,338 & 461 & $\begin{array}{l}\mathrm{MS}^{2}[461]: 446(1), 341(4), 323(3), 299(100) ; \mathrm{MS}^{3}[299]: 284(100) ; \mathrm{MS}^{4}[284]: 256(40), \\
151(5) ; \mathrm{MS}^{5}[256]: 239(4), 227(100), 211(20), 200(10), 122(60), 94(2)\end{array}$ & Chrysoeriol-7- $\beta-0$-glucoside \\
\hline 8 & 11.3 & 267,332 & 445 & $\operatorname{MS}^{2}[445]: 269(100), 175(5) ; \operatorname{MS}^{3}[269]: 225(5), 183(1)$ & Apigenin-7- $\beta-O$-glucuronide \\
\hline 9 & 11.5 & 290,328 & 359 & $\begin{array}{l}\operatorname{MS}^{2}[359]: 223(15), 197(25), 179(30), 161(100), 133(4) ; \mathrm{MS}^{3}[179]: 161(25), 151(<1) \\
\text { 135(100) }\end{array}$ & Rosmarinic acid \\
\hline 10 & 12.5 & 290,323 & 537 & $\begin{array}{l}\mathrm{MS}^{2}[537]: 493 ; \mathrm{MS}^{3}[493]: \text { 359(100), 357(15), 313(10), 295(3), 269(<1), 247(<1), 179(1), } \\
161(1) ; \mathrm{MS}^{4}[359]: 249(5), 223(10), 197(15), 179(25), 161(100), 135(5)\end{array}$ & $3^{\prime}-0$-(8"-Z-Caffeoyl)rosmarinic acid \\
\hline
\end{tabular}




\subsubsection{Phenolic acid derivatives}

In accordance with literature data, the rosmarinic acid, which was herein identified by its retention time, UV-vis spectrum, ESI-MS ${ }^{\mathrm{n}}$ (Table 1) and NMR (Table 2) data, represented a major HPLC fraction in the T. $x$ citriodorus ethanolic extract (fraction 9, Fig. 1). To our knowledge, this compound has been previously detected in Thymus serpyllum, Thymus sipyleus, Thymus quinquecostatus and Thymus vulgaris L., and has been shown to account between 3.4 and $22 \mathrm{mg} / \mathrm{g}$ of dry plant, in the latter species (Pereira \& Cardoso, 2013). Besides this phenolic acid, the $T$. $\mathbf{x}$ citriodorus ethanolic extract also contained an uncommon caffeoyl derivative of rosmarinic acid (fraction 10), which was assigned based on its UV-vis spectrum, as compared to that of rosmarinic acid, plus interpretation of its ESI-MS ${ }^{\mathrm{n}}$ fragmentation pattern (Dapkevicius et al., 2002). Most probably, this compound corresponds to $3^{\prime}-O-\left(8^{\prime \prime}-Z-\right.$ caffeoyl)rosmarinic acid, which has been previously detected in the leaves of T. vulgaris L. (Dapkevicius et al., 2002).

\subsubsection{Flavones}

Flavones were also detected as major phenolic component of the T. $x$ citriodorus ethanolic extract. In more detail, the extract contained three luteolin derivatives, which were eluted in fractions 4 and 6 $\left([\mathrm{M}-\mathrm{H}]^{-}\right.$ion at $m / z 447$ in fraction 4 and $[\mathrm{M}-\mathrm{H}]^{-}$ions at $m / z 461$ and $m / z 447$ in fraction 6). The $[\mathrm{M}-\mathrm{H}]^{-}$ion at $m / z 447$ in the latter fraction was assigned to luteolin-7-O-glucoside, since the retention time and $\mathrm{MS}^{\mathrm{n}}$ data matched with those of the reference compound. In turn, the $[\mathrm{M}-\mathrm{H}]^{-}$ion at $\mathrm{m} / \mathrm{z} 447$ in fraction 4 was assigned to luteolin-5- $\beta-O$-glucoside, based on the gathered $1 \mathrm{D}$ (Table 2 ) and 2D NMR spectral data. From these spectra it was possible to assign the major part of the ${ }^{1} \mathrm{H}$ and ${ }^{13} \mathrm{C}$ resonances, mainly obtained from the connectivities found in the $\mathrm{HMBC}$ spectrum of this compound (the connectivity between $\mathrm{H}-1$ " and $\mathrm{C}-5$ allowed us to assign the sugar position on the flavone skeleton). The coupling constant of the $\mathrm{H}-1$ of the sugar moiety $(J=7.3 \mathrm{~Hz})$ indicates the presence of the $\beta$-anomer. To our knowledge, for Thymus plants the latter luteolin derivative has only been previously detected in T. sipyleus and in T. praecox (Ozgen et al., 2011).

Moreover, the HPLC-DAD-ESI-MS ${ }^{\mathrm{n}}$ analysis allowed to assign the $[\mathrm{M}-\mathrm{H}]^{-}$ion at $m / z 461$ in fraction 6 to luteolin-O-hexuronyl, as the product ion at $m / z 285$ was obtained by the loss of $176 \mathrm{Da}$ (Fig. 2A). Additional information on the sugar moiety (glucuronic acid), as well as its linkage position on the flavone skeleton (7-) was elucidated by 1D and 2D NMR analysis (see Fig. 2B for ${ }^{1} \mathrm{H}$ RMN and gHSQC spectra). These NMR spectra allowed us to assign the major part of the proton and carbon resonances (Table 2), but due to the small quantity of the sample we could not found the HMBC correlation between $\mathrm{H}-1$ " from the sugar residue and the $\mathrm{C}-7$ of the flavone. However, the assigned chemical shifts are compatible with a 7-glucuronide (Agrawal \& Bansal, 1989; Lu \& Foo, 1999). H-1" of the sugar residue appears as a broad singlet, which is only compatible with an $\alpha$-configuration. Note that despite the fact that luteolin-O-glucuronide has been previously described in several Thymus plants (Justesen, 2000; Miron, Plaza, Bahrim, Ibanez, \& Herrero, 2011), only the 7-O- 3 -isomer has been previously identified by NMR analysis (Fecka \& Turek, 2008; Ozgen et al., 2011).

Besides the luteolin derivatives, the T. $x$ citriodorus ethanolic extract also contained another flavone hexuronyl derivative (fraction $8,[\mathrm{M}-\mathrm{H}]^{-}$ion at $m / z 445$ ). In this particular case, the $\mathrm{MS}^{2}$ spectrum showed a main ion at $m / z 269$, and the latter followed a fragmentation pattern consistent to that of apigenin. According to the NMR determinations (Guvenalp, Ozbek, Kuruuzum-Uz, Kazaz, \& Demirezer, 2009) the $[\mathrm{M}-\mathrm{H}]^{-}$ion at $m / z 445$ was assigned to apigenin-7- $\beta-0$-glucuronide, which, for the Thymus genus, has only been previously reported in T. vulgaris L. and T. serpyllum (Justesen, 2000; Miron et al., 2011).

Notably our study also allowed to detect, for the first time in Thymus plants, a hexoside derivative of the methylated flavone chrysoeriol. This compound was eluted in fraction 7 and appeared

Table 2

Chemical shifts $(\delta)$ of phenolic compounds of T. $x$ citriodorus ethanolic extract, which eluted in fractions 4, 6, 7, 8 and 9 (in DMSO-d 6 ).

\begin{tabular}{|c|c|c|c|c|c|c|c|c|c|c|c|}
\hline \multirow{3}{*}{$\begin{array}{l}\text { Compound } \\
\text { Atom }\end{array}$} & \multirow{2}{*}{\multicolumn{2}{|c|}{$\frac{4}{\text { Luteolin-5- } \beta-O-\text { glucoside }}$}} & \multirow{2}{*}{\multicolumn{2}{|c|}{$\begin{array}{l}6 \\
\begin{array}{l}\text { Luteolin-7- } \alpha-O- \\
\text { glucuronide }\end{array}\end{array}$}} & \multirow{2}{*}{\multicolumn{2}{|c|}{$\frac{7}{\text { Chrysoeriol-7- } \beta \text {-O-glucoside }}$}} & \multirow{2}{*}{\multicolumn{2}{|c|}{$\begin{array}{l}8 \\
\begin{array}{l}\text { Apigenin-7- } \beta-O- \\
\text { glucuronide }\end{array}\end{array}$}} & \multirow[b]{3}{*}{ Atom } & \multicolumn{2}{|l|}{9} \\
\hline & & & & & & & & & & \multicolumn{2}{|c|}{ Rosmarinic Acid } \\
\hline & $\begin{array}{l}{ }^{13} \mathrm{C} \\
(\mathrm{ppm})\end{array}$ & $\begin{array}{l}{ }^{1} \mathrm{H} \\
(\mathrm{ppm})\end{array}$ & $\begin{array}{l}{ }^{13} \mathrm{C} \\
(\mathrm{ppm})\end{array}$ & $\begin{array}{l}{ }^{1} \mathrm{H} \\
(\mathrm{ppm})\end{array}$ & $\begin{array}{l}{ }^{13} \mathrm{C} \\
(\mathrm{ppm})\end{array}$ & $\begin{array}{l}{ }^{1} \mathrm{H} \\
(\mathrm{ppm})\end{array}$ & $\begin{array}{l}{ }^{13} \mathrm{C} \\
(\mathrm{ppm})\end{array}$ & $\begin{array}{l}{ }^{1} \mathrm{H} \\
(\mathrm{ppm})\end{array}$ & & $\begin{array}{l}{ }^{13} \mathrm{C} \\
(\mathrm{ppm})\end{array}$ & $\begin{array}{l}{ }^{1} \mathrm{H} \\
(\mathrm{ppm})\end{array}$ \\
\hline 2 & 161.2 & - & 164.5 & - & 160.8 & - & 164.3 & - & 1 & 130.4 & - \\
\hline 3 & 105.3 & $6.50(\mathrm{~s})$ & 103.1 & $6.76(\mathrm{~s})$ & 106.2 & $6.58(\mathrm{~s})$ & 103.1 & $6.88(\mathrm{~s})$ & 2 & 114.5 & 6.65 (br s) \\
\hline 4 & 176.6 & - & 182.0 & - & 176.1 & - & ni & - & 3 & 144.7 & $\mathrm{ni}$ \\
\hline 5 & 158.7 & - & 161.2 & $13.00(\mathrm{~s})$ & ni & $12.97(\mathrm{~s})$ & ni & ni & 4 & 143.5 & ni \\
\hline 6 & 105.2 & 6.73 (br s) & 99.5 & 6.45 (br s) & 99.5 & 6.43 (br s) & 104.4 & $6.81(\mathrm{~J} 2.0 \mathrm{~Hz})$ & 5 & 116.4 & $6.59(\mathrm{~d}, J 7.6 \mathrm{~Hz})$ \\
\hline 7 & ni & $\begin{array}{l}\mathrm{OH} \\
8.45(\mathrm{~s})\end{array}$ & 162.8 & - & ni & ni & ni & ni & 6 & 120.0 & $6.47(\mathrm{br} \mathrm{d}, J 7.6 \mathrm{~Hz})$ \\
\hline 8 & 98.5 & 6.61 (br s) & 94.6 & 6.80 (br s) & 94.6 & 6.83 (br s) & 98.1 & $6.73(\mathrm{~J} 2.0 \mathrm{~Hz})$ & 7 & 36.3 & $\begin{array}{l}3.00(\mathrm{~d}, J 12.4 \mathrm{~Hz}) \\
2.70(\mathrm{~d}, J 12.4 \text { and } 10.1 \mathrm{~Hz})\end{array}$ \\
\hline 9 & ni & - & 157.1 & - & ni & - & ni & - & 8 & 76.2 & $4.79(\mathrm{br} \mathrm{d}, J 10.1 \mathrm{~Hz})$ \\
\hline 10 & 107.4 & - & 105.4 & - & $\mathrm{ni}$ & - & $\mathrm{ni}$ & - & 9 & ni & ni \\
\hline $1^{\prime}$ & 121.1 & - & 121.4 & - & 123.2 & - & ni & - & $1^{\prime}$ & 125.7 & - \\
\hline $2^{\prime}$ & 112.9 & $7.34(\mathrm{~s})$ & 113.6 & $7.43($ br d) & 112.8 & 7.40 (br s) & 128.4 & $7.97(\mathrm{~d}, J 8.7 \mathrm{~Hz})$ & $2^{\prime}$ & 114.5 & 7.02 (br s) \\
\hline $3^{\prime}$ & 145.8 & $\begin{array}{l}\mathrm{OH} \\
5.12 \text { (brs) }\end{array}$ & 145.8 & 9.48 (br s) & 146.8 & - & 116.0 & $6.94(\mathrm{~d}, J 8.7 \mathrm{~Hz})$ & $3^{\prime}$ & 148.2 & ni \\
\hline $4^{\prime}$ & 149.8 & $\begin{array}{l}\mathrm{OH} \\
5.12 \text { (brs) }\end{array}$ & 150.0 & $\begin{array}{l}10.01 \\
\text { (br s) }\end{array}$ & 150.7 & ni & 161.5 & - & $4^{\prime}$ & 145.7 & ni \\
\hline $5^{\prime}$ & 115.8 & $6.85(\mathrm{~d}, J 7.8 \mathrm{~Hz})$ & 115.9 & $6.90(\mathrm{~d}, J 8.4 \mathrm{~Hz})$ & 110.5 & $7.07(\mathrm{~d}, J 8.2 \mathrm{~Hz})$ & ni & ni & $5^{\prime}$ & 115.4 & $6.74(\mathrm{~d}, J 8.4 \mathrm{~Hz})$ \\
\hline $6^{\prime}$ & 118.6 & $7.35(\mathrm{~d}, J 7.8 \mathrm{~Hz})$ & 119.2 & $7.45(\mathrm{~d}, J 8.4 \mathrm{~Hz})$ & 118.4 & $7.49(\mathrm{br} \mathrm{d}, J 8.2 \mathrm{~Hz})$ & $\mathrm{ni}$ & ni & $6^{\prime}$ & 121.0 & $6.94(\mathrm{~d}, J 8.4 \mathrm{~Hz})$ \\
\hline Sugar & & & & & & & & & $7^{\prime}$ & 143.5 & $7.34(\mathrm{~d}, \mathrm{~J} 15.9 \mathrm{~Hz})$ \\
\hline $1^{\prime \prime}$ & 105.1 & $4.67(\mathrm{~d}, J 7.3 \mathrm{~Hz})$ & 99.5 & 5.19 (br s) & 103.1 & $4.68(\mathrm{~d}, J 7.0 \mathrm{~Hz})$ & 99.5 & $5.03(\mathrm{~d}, J 7.3 \mathrm{~Hz})$ & $8^{\prime}$ & 115.1 & $6.16(\mathrm{~d}, \mathrm{~J} 15.9 \mathrm{~Hz})$ \\
\hline $2^{\prime \prime}$ & 73.6 & $*$ & 73.0 & $*$ & $\mathrm{ni}$ & ni & ni & ni & $9^{\prime}$ & 166.2 & - \\
\hline $3^{\prime \prime}$ & 75.6 & $*$ & 75.2 & $*$ & $\mathrm{ni}$ & ni & ni & ni & & & \\
\hline $4^{\prime \prime}$ & 69.8 & $*$ & 72.9 & $*$ & $\mathrm{ni}$ & ni & $\mathrm{ni}$ & ni & & & \\
\hline $5^{\prime \prime}$ & 77.6 & $*$ & 72.8 & $*$ & ni & - & ni & - & & & \\
\hline $6^{\prime \prime}$ & 60.8 & $*$ & ni & - & ni & ni & ni & ni & & & \\
\hline
\end{tabular}

* Under the peak of water.

ni - not identified. 


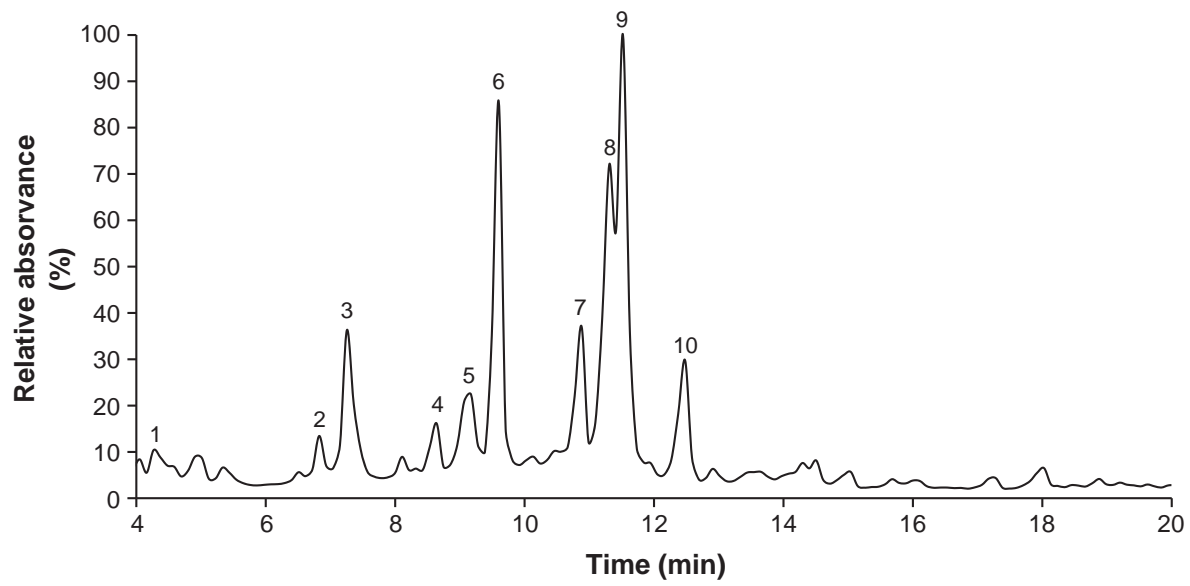

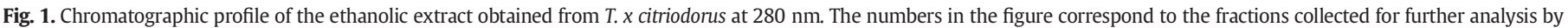
ESI-MS ${ }^{\mathrm{n}}$ and NMR.

in the ESI-MS spectrum as the $[\mathrm{M}-\mathrm{H}]^{-}$ion at $m / z \quad 461$ that fragmented to a main product ion at $m / z 299$ ( -162 Da, loss of hexose). Moreover, the fragmentation pattern of this product ion was similar to that of chrysoeriol (Plazonic et al., 2009). This information was corroborated by the NMR analysis, which also allowed us to assign the exact structure of this flavone to chrysoeriol-7- $\beta-O$ glucoside (Table 2 ). The $\beta$-configuration of the sugar residue is based on the coupling of the $\mathrm{H}-1^{\prime \prime}, J=7.3 \mathrm{~Hz}$.

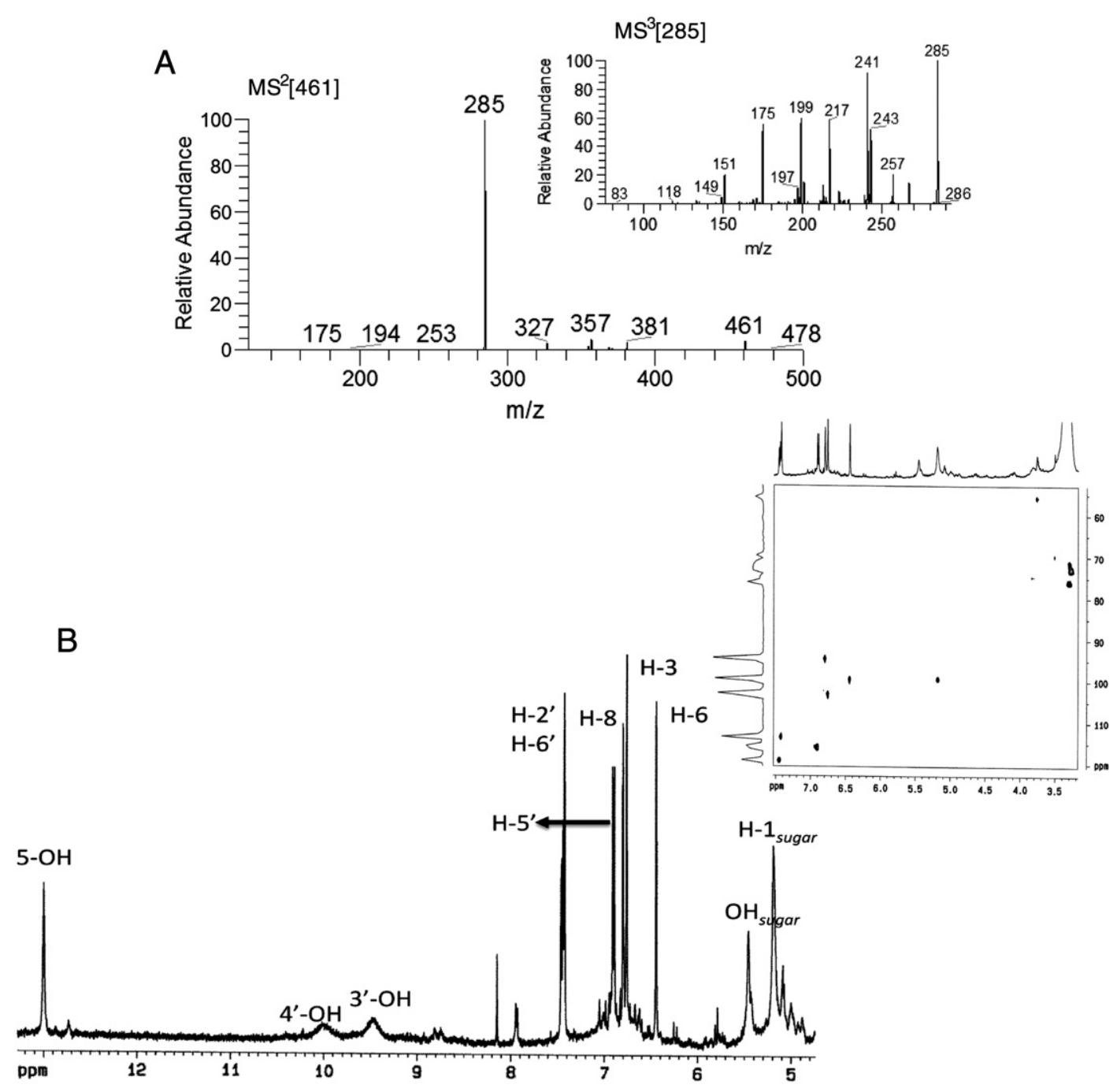

Fig. 2. Mass spectrum of (A) ESI-MS ${ }^{2}$ of the $[\mathrm{M}-\mathrm{H}]^{-}$ion at $m / z 461$ and (inset) ESI-MS ${ }^{3}$ of the $[\mathrm{M}-\mathrm{H}]^{-}$ion at $m / z$ 285; (B) expansion of the ${ }^{1} \mathrm{H} N M R$ and (inset) $g \mathrm{HSQC}$ spectra of fraction 6 eluted on HPLC-DAD. 


\subsubsection{Flavanones}

Three glycoside derivatives of eriodictyol have been previously described in the genus Thymus, namely the eriodictyol-7-O-glucoside (Fecka \& Turek, 2008), the eriodictyol-7-O-rutinoside (Wang, Li, Ho, Peng, \& Ho, 1998) and the eriodictyol-7-O-glucuronide (Justesen, 2000). Nevertheless, the results now obtained show that three of the four eriodictyol derivatives detected in the ethanolic extract of T. $x$ citriodorus differ from those previously reported for the other species of Thymus. Indeed, the ESI-MS analysis of fraction 1 showed that the $[\mathrm{M}-\mathrm{H}]^{-}$ion at $m / z 611$ and its $\mathrm{MS}^{2}$ and $\mathrm{MS}^{3}$ fragmentation data revealed the loss of two hexose molecules (product ions at $\mathrm{m} / \mathrm{z}$ 449 and $m / z$ 287). Moreover, the ESI-MS ${ }^{3}$ spectrum of the $[\mathrm{M}-\mathrm{H}]^{-}$ ion at $\mathrm{m} / \mathrm{z} 449$ was similar to that of authentic eriodictyol-7-0glucoside and hence, these data indicates the elution in fraction 1 of an eriodictyol dihexoside with $\mathrm{O}$-glycosyl linkages. Note that, flavonoid diglycosides with $O$-linkages (di-O-glycosides and $O$-diglycosides), can be distinguished by their product ion spectra (Vukics \& Guttman, 2008), through the analysis of the $[\mathrm{M}-\mathrm{H}-162]^{-},[\mathrm{M}-\mathrm{H}-180]^{-}$ and $[\mathrm{M}-\mathrm{H}-324]^{-}$ions. A high relative intense product ion [M $\mathrm{H}-162]^{-}$and the absence of $[\mathrm{M}-\mathrm{H}-180]^{-}$at the $\mathrm{MS}^{2}$ spectrum, as observed for the ion at $m / z 611$, indicate the presence of a flavonoid di-O-hexoside and thus, the present results confirm the detection, for the first time in Thymus, of an eriodictyol-di-O-hexoside.

Eriodictyol-O-monohexosides were detected in fractions 2 and 3. As observed in Table 1, the ESI-MS spectra of both fractions showed a $[\mathrm{M}-\mathrm{H}]^{-}$ion at $m / z 449$, and their $\mathrm{MS}^{2}$ spectrum revealed the ion at $m / z$ 287, which corresponds to the eriodictyol aglycone. The UV-vis data of these two peaks were similar to that of the eriodictyol-7-Oglucoside standard, but fractions 2 and 3 eluted before that compound, indicating that two new eriodictyol-O-hexosides must be present in T. $x$ citriodorus. In fact, to our knowledge, eriodictyol-7-0-glucoside is the only described glucoside derivative of eriodictyol in Lamiaceae family. Besides the above described O-hexosyl derivatives of eriodictyol, the $T$. $x$ citriodorus ethanolic extract also contained an $O$-hexuronyl of this flavanone, but this appeared only as a minor constituent of fraction 5. Eriodictyol-O-glucuronide has been previously found in thyme and wild thyme (Justesen, 2000; Miron et al., 2011), but no quantitative information has been delivered on that compound on those plants. Besides eriodictyol derivatives, the flavavone naringenin- $O$-hexoside was also identified as a phenolic constituent of the T. $x$ citriodorus ethanolic extract. Its $[\mathrm{M}-\mathrm{H}]^{-}$ion was observed in fraction 5 at $\mathrm{m} / \mathrm{z}$ 433 and this fragmented to the ion at $m / z 271$ ( $-162 \mathrm{Da}$ ). Moreover, the $\mathrm{MS}^{3}$ spectrum of the ion at $m / z 271$ (main ions at $m / z 227,151$ and 107), indicated a correspondence to authentic naringenin (Fabre, Rustan, de Hoffmann, \& Quetin-Leclercq, 2001). Despite the fact that the detailed structure of this compound could not be accomplished in the present study, for sure, this does not correspond to the unique naringenin glucoside described so far in Thymus, i.e. the naringenin-70 -glucoside (Fecka \& Turek, 2008), as it eluted before the naringenin7-O-glucoside standard (10.5 min).

\subsubsection{Flavonols}

In accordance to the previous studies focusing on Thymus plants, the ethanolic extract of T. $x$ citriodorus was very poor in flavonols. In the present study, the unique flavonol was detected as a minor component of fraction 2. Its corresponding molecular ion was observed for $m / z 507$ and its $\mathrm{MS}^{2}$ spectrum showed product ions formed by the loss of a hexose moiety [ion at $m / z 345(-162 \mathrm{Da}$ ) and ion at $\mathrm{m} / z 327$ (simultaneous loss of 162 and $18 \mathrm{Da}$ )]. Considering that the ion at $\mathrm{m} / z 345$ can diagnose the quercetagetin dimethyl ether (Parejo, Jauregui, Viladomat, Bastida, \& Codina, 2004), the overall data suggests the presence of the flavonol quercetagetin dimethyl ether-O-hexoside in $\mathrm{T}$. $x$ citriodorus. Methyl derivatives of quercetagetin, namely quercetagetin 3,7-dimethyl ether, have been described to occur in the Lamiaceae family (Grayer et al., 2010), however this is the first time that this class of compounds has been found in the genus Thymus.

\subsection{HPLC method - validation and quantification of phenolic compounds} by HPLC-DAD

For the five used phenolic standards, the adjusted $R^{2}$ values were around 0.999 , suggesting a good linearity of the analytical method in the concentration range tested (Table 3 ) and showing that the HPLC method allows the quantification of the evaluated phenolic compounds, in case of their presence in the plant samples. All the calibration linear models were significant $(\mathrm{P}<0.001)$ as well as their slope values $(\mathrm{P}<0.001)$ and the intercept values $(\mathrm{P}<0.003$, except for apigenin$O$-glucoside with $\mathrm{P}=0.228$ ). Finally, the covariance analysis for each phenolic standard (data not shown) indicated that the calibration curves of one week interval were not statistically different ( $P \geq 0.330)$, meaning that the same calibration curve could be used during at least one week for quantification purposes. Table 3 also shows the LOD and LOQ values, which were always lower than the lowest standard concentration tested in the dynamic interval of the calibration curve, indicating a satisfactory sensitivity towards each phenolic standard.

The relative standard deviation percentage (\%RSD) values of repeatability and of immediate precision assays were carried out with the five phenolic standards, regarding the instrumental precision evaluation. In repeatability, \%RSD values varied from 2 to $5 \%$ and from 0.3 to $2 \%$, for the retention time and the peak area, respectively. Concerning the immediate precision, the \%RSD values of the retention times and peak areas were between $3-4 \%$ and $1-2 \%$, respectively. These results are similar to those described by Du et al. (2010) and Gobbo-Neto and Lopes (2008) for phenolic compounds in Lamiaceae and Asteraceae plants, respectively. Since the \%RSD values were lower than $5 \%$, it is possible to conclude that the chromatographic instrument presents a satisfactory precision (Ermer \& Miller, 2005).

The \%RSD values for repeatability, immediate precision and intermediate precision assays of the method (extraction plus HPLC analysis) are given in Table 3. As the values for the first two parameters were lower than $12 \%$, it can be concluded that the precision of the method was satisfactory. Regarding intermediate precision, the \%RSD values varied from $6 \%$ to $41 \%$, being in general lower than $20 \%$. The highest values [33\% and $41 \%$ for eriodictyol-7-O-glucoside and 3'-O-(8"-Z-Caffeoyl) rosmarinic acid, respectively] could be due to the low content of these compounds (Table 3 ), as well as to the nature of the extraction process and the complexity of the chromatographic analysis (Aldai, Osoro, Barrón, \& Nájera, 2006). In fact, depending on the samples complexity, \%RSD values up to $20 \%$ are acceptable for quantitative chromatographic analysis of residual analytes (Ribani, Bottoli, Collins, Jardim, \& Melo, 2004). Therefore, it can be stated that the proposed method is able to quantify the major phenolic compounds detected in T. $x$ citriodorus samples with overall satisfactory precision.

Regarding the two absolute recovery assays carried out (addition of $0.986 \mathrm{mg}$ of luteolin-7-O-glucoside and $0.121 \mathrm{mg}$ of rosmarinic acid or $1.548 \mathrm{mg}$ of luteolin-7-0-glucoside and $0.555 \mathrm{mg}$ of rosmarinic acid to $2.04 \pm 0.02 \mathrm{~g}$ of dry plant samples, respectively) recoveries were of $120 \%$ and $60 \%$ or $121 \%$ and $79 \%$ for luteolin-7-O-glucoside and rosmarinic acid, respectively, with \%RSD values between $2 \%$ and $4 \%$. These results are acceptable as, depending on the complexity of the chromatographic method and the sample matrix, recovery values between $50 \%$ and $120 \%$ are adequate if their \%RSD values are lower than 15\% (Ribani et al., 2004).

The mean total phenolic contents ( $\mathrm{mg} / \mathrm{g}$ of extract) of the T. $x$ citriodorus plant were evaluated from the intermediate precision assays and are presented in Table 3. According to the results, the identified phenolic compounds accounted for $44 \mathrm{mg} / \mathrm{g}$ of the ethanolic extract (or $7.5 \mathrm{mg} / \mathrm{g}$ of dried plant). Similarly to other Thymus species, such as T. vulgaris L. and T. spicata (Dorman et al., 2004; Fecka \& Turek, 2008), the ethanolic extract of T. $x$ citriodorus was mostly enriched in rosmarinic acid (10.4 $\pm 0.6 \mathrm{mg} / \mathrm{g}$ extract). Still, our results also showed 
Table 3

Linearity, LOD, LOQ and instrumental and method precisions.

\begin{tabular}{|c|c|c|c|c|c|c|c|}
\hline \multicolumn{8}{|c|}{ Instrumental precision study } \\
\hline Standard compound & Range concentration $(\mu \mathrm{g} / \mathrm{mL})$ & $\mathrm{n}^{\mathrm{a}}$ & Slope $^{\mathrm{b}}$ (area counts/mg) & Intercept $^{\mathrm{b}}$ (area counts/mg) & $\mathrm{R}^{2}$ & LOD $(\mu \mathrm{g} / \mathrm{mL})$ & $\mathrm{LOQ}(\mu \mathrm{g} / \mathrm{mL})$ \\
\hline E-70-G & $10.0-135.9$ & 5 & $144( \pm 1) \cdot 10^{6}$ & $-43( \pm 9) .10^{4}$ & 0.9999 & 2.0 & 6.2 \\
\hline N-70-G & $5.0-67.9$ & 5 & $1797( \pm 6) \cdot 10^{5}$ & $-19( \pm 2) \cdot 10^{4}$ & 0.9999 & 1.0 & 3.0 \\
\hline L-7O-G & $45.3-300.0$ & 5 & $663( \pm 7) \cdot 10^{5}$ & $-4( \pm 1) \cdot 10^{5}$ & 0.9984 & 12.4 & 37.7 \\
\hline A-70-G & $2.5-160.0$ & 5 & $848( \pm 8) \cdot 10^{5}$ & $-1( \pm 6) \cdot 10^{4}$ & 0.9988 & 7.3 & 22.1 \\
\hline RA & $14.9-120.0$ & 5 & $1343( \pm 9) \cdot 10^{5}$ & $-27( \pm 6) \cdot 10^{4}$ & 0.9995 & 3.3 & 9.9 \\
\hline \multicolumn{8}{|c|}{ Instrumental precision study (intra- and inter-days variability of standard solutions injections) } \\
\hline \multirow[t]{3}{*}{ Standard compound } & \multirow[t]{3}{*}{ Concentration $(\mu \mathrm{g} / \mathrm{mL})$} & & \multicolumn{5}{|l|}{ \%RD } \\
\hline & & & \multicolumn{2}{|l|}{ Repeatability $(\mathrm{n}=5)$} & \multicolumn{3}{|c|}{ Immediate precision $(\mathrm{n}=9)$} \\
\hline & & & Retention time (min) & Peak area & Retentior & ne (min) & Peak area \\
\hline \multirow[t]{3}{*}{ E-7O-G } & 10 & & 1.1 & 1.4 & 4.8 & & 2.1 \\
\hline & 30 & & 1.3 & 0.9 & 3.1 & & 2.1 \\
\hline & 80 & & 2.5 & 1.5 & 3.6 & & 1.7 \\
\hline \multirow[t]{3}{*}{ N-70-G } & 5 & & 2.3 & 2.1 & 4.3 & & 2.6 \\
\hline & 40 & & 3.3 & 0.7 & 3.1 & & 1.8 \\
\hline & 50 & & 1.3 & 0.5 & 3.1 & & 1 \\
\hline \multirow[t]{3}{*}{ L-7O-G } & 45 & & 0.6 & 1.0 & 4.4 & & 0.9 \\
\hline & 100 & & 1.3 & 0.5 & 3.4 & & 1.2 \\
\hline & 300 & & 3.5 & 0.2 & 3.7 & & 1.6 \\
\hline \multirow[t]{3}{*}{ A-70-G } & 10 & & 0.2 & 1.6 & 3.4 & & 2.5 \\
\hline & 80 & & 3.4 & 1.1 & 4.3 & & 1.6 \\
\hline & 160 & & 0.9 & 1.1 & 3.9 & & 2 \\
\hline \multirow[t]{3}{*}{ RA } & 15 & & 2.5 & 0.7 & 3.5 & & 3.2 \\
\hline & 30 & & 2.1 & 0.7 & 3 & & 0.8 \\
\hline & 150 & & 1.2 & 0.9 & 3.1 & & 1.3 \\
\hline
\end{tabular}

Method precision study (intra- and inter-days variability of extractions obtained from a Thymus sample)

\begin{tabular}{|c|c|c|c|c|c|c|}
\hline \multicolumn{2}{|c|}{ Identified compound } & \multirow{2}{*}{$\begin{array}{l}\text { Standard compound } \\
\text { (used to quantify) }\end{array}$} & \multirow{2}{*}{$\begin{array}{l}\text { Mean content }{ }^{\mathrm{C}} \\
\text { (mg/g extract) }\end{array}$} & \multicolumn{3}{|c|}{ \%RSD for compound concentrations } \\
\hline Fraction number & Compound name & & & $\begin{array}{l}\text { Repeatability } \\
(\mathrm{n}=5)\end{array}$ & $\begin{array}{l}\text { Immediate precision } \\
(\mathrm{n}=9)\end{array}$ & $\begin{array}{l}\text { Intermediate precision } \\
(\mathrm{n}=18)\end{array}$ \\
\hline 1 & Eriodictyol-di-O-hexoside & E-70-G & $0.71 \pm 0.07$ & 5 & 7 & 11 \\
\hline 2 & Eriodictyol-O-hexoside & E-70-G & $1.3 \pm 0.4$ & 10 & 12 & 33 \\
\hline 3 & Eriodictyol-O-hexoside & E-70-G & $3.7 \pm 0.5$ & 4 & 7 & 12 \\
\hline 4 & Luteolin-5- $\beta-O$-glucoside & L-70-G & $3.2 \pm 0.5$ & 2 & 4 & 16 \\
\hline 5 & Naringenin- $O$-hexoside & $\mathrm{N}-70-\mathrm{G}$ & $1.8 \pm 0.2$ & 6 & 6 & 9 \\
\hline 6 & Luteolin-7- $\alpha-0$-glucuronide & L-7O-G & $12 \pm 2$ & 4 & 5 & 20 \\
\hline 8 & Apigenin-7- $\beta-O$-glucuronide & A-70-G & $9 \pm 2$ & 6 & 7 & 20 \\
\hline 9 & Rosmarinic acid & RA & $10.4 \pm 0.6$ & 6 & 5 & 6 \\
\hline 10 & 3'-O-(8"-Z-Caffeoyl)rosmarinic acid & RA & $2.3 \pm 0.9$ & 4 & 4 & 41 \\
\hline Total & - & - & $44 \pm 4$ & - & - & - \\
\hline
\end{tabular}

E-70-G, eriodictyol-7-O-glucoside; N-7O-G, naringenin-7-O-glucoside; L-70-G, luteolin-7-O-glucoside; A-70-G, apigenin-7-O-glucoside; RA, rosmarinic acid.

a Number of points used for the regression of standard solutions. Injections were done in triplicate.

b The standard deviation in the slope and intercept of the regression line is shown in parentheses.

c Mean values \pm standard deviations.

that in contract to the majority of the previously studied Thymus plants, the non-common isomeric form of luteolin-O-hexoside, i.e. the luteolin7 - $\alpha$-O-glucuronide, as well as apigenin-7- $\beta$ - 0 -glucuronide, were also major phenolic constituents of the extract, accounting for $12 \pm 2 \mathrm{mg} /$ g extract and $9 \pm 2 \mathrm{mg} / \mathrm{g}$ extract, respectively.

\section{Conclusions}

The phenolic composition of an ethanolic extract of T. $x$ citriodorus was described in detail for the first time, by means of HPLC-DAD plus ESI-MS, MS ${ }^{\mathrm{n}}$ and NMR analysis. The in-house validated HPLC-DAD method showed good linearity for the tested reference compounds as well as satisfactory repeatability and immediate precision values, for both instrument and method. Furthermore, the satisfactory results of intermediate precision analysis and recovery assays indicated that the chromatographic method could be used to quantify the main phenolic compounds of T. $x$ citriodorus with adequate precision and accuracy. The fractionation of the ethanolic extract by HPLC-DAD reversed phase and the analysis of the collected freeze-dried fractions by electrospray mass spectrometry in the negative mode allowed us to identify thirteen phenolic compounds, which include the phenolic acid rosmarinic acid and one of its derivatives, as well as derivatives of the flavones luteolin, chrysoeriol and apigenin, of the flavanones eriodictyol and naringenin and of the flavonol quercetagetin. Similarly to other Thymus species, rosmarinic acid represented a major phenolic constituent of the T. $x$ citriodorus ethanolic extract. However, our results also suggest that this plant species produces high amounts of non-common Thymus phenolics, including the $7-\alpha-O$-glucuronide derivative of luteolin and apigenin-7- $\beta$ - $O$-glucuronide. As the majority of these compounds are described in literature as health-benefit compounds, we propose that this Thymus species can be used as nutraceutical agent with potential interest for food and pharmaceutical industries.

\section{Abbreviations used}

CID collision-induced dissociation

DAD diode array

ESI-MS electrospray ionization-mass spectrometry

MS $^{\mathrm{n}} \quad$ tandem mass spectrometry

GAE gallic acid equivalent 
HPLC high-performance liquid chromatography

LC liquid chromatography

LOD limit of detection

LOQ limit of quantification

MS mass spectrometry

RSD relative standard deviation

\section{Acknowledgments}

The authors gratefully acknowledge the financial support provided by the Foundation for Science and Technology (FCT) to CERNAS (Project PEst-OE/AGR/UI0681/2011) and of FCT, the European Union, QREN, FEDER, COMPETE, for funding the Organic Chemistry Research Unit (QOPNA) (project PEst-C/QUI/UI0062/2013; FCOMP-01-0124-FEDER037296) and the Portuguese National NMR Network (RNRMN). Olívia R. Pereira was supported by a PhD grant (SFRH/PROTEC/49600/2009). Authors are also grateful to Eng Jorge Sá Morais for technical support in the HPLC analysis.

\section{References}

Agrawal, P. K., \& Bansal, M. C. (1989). Chapter 6: Flavonoid glycosides. In P. K. Agrawal (Ed.), Carbon-13 NMR of flavonoids, Vol. 28. (pp. 283-364)Amsterdam: John Wiley \& Sons, Ltd.

Aldai, N., Osoro, K., Barrón, L. J. R., \& Nájera, A. I. (2006). Gas-liquid chromatographic method for analysing complex mixtures of fatty acids including conjugated linoleic acids (cis9trans11 and trans10cis12 isomers) and long-chain $(n-3$ or $n-6)$ polyunsaturated fatty acids: Application to the intramuscular fat of beef meat. Journal of Chromatography. A, 1110(1-2), 133-139.

Celtnet (2013). Celtnet recipes. Retrieved from. http://www.celtnet.org.uk/recipes/.

Dapkevicius, A., van Beek, T. A., Lelyveld, G. P., van Veldhuizen, A., de Groot, A., Linssen, J. P. H., et al. (2002). Isolation and structure elucidation of radical scavengers from Thymus vulgaris leaves. Journal of Natural Products, 65(6), 892-896.

Dorman, H. J.D., Bachmayer, O., Kosar, M., \& Hiltunen, R. (2004). Antioxidant properties of aqueous extracts from selected Lamiaceae species grown in Turkey. Journal of Agricultural and Food Chemistry, 52(4), 762-770.

Du, Y. F., Liu, P. W., Yuan, Z. F., Jin, Y. R., Zhang, X. W., Sheng, X. N., et al. (2010). Simultaneous qualitative and quantitative analysis of 28 components in Isodon rubescens by HPLC-ESI-MS/MS. Journal of Separation Science, 33(4-5), 545-557.

Ermer, J., \& Miller, J. M. (2005). Method validation in pharmaceutical analysis: A guide to best practice. Weinheim: WILEY-VCH Verlag GmbH \& Co.

Fabre, N., Rustan, I., de Hoffmann, E., \& Quetin-Leclercq, J. (2001). Determination of flavone, flavonol, and flavanone aglycones by negative ion liquid chromatography electrospray ion trap mass spectrometry. Journal of the American Society for Mass Spectrometry, 12(6), 707-715.

Fecka, I., \& Turek, S. (2008). Determination of polyphenolic compounds in commercial herbal drugs and spices from Lamiaceae: Thyme, wild thyme and sweet marjoram by chromatographic techniques. Food Chemistry, 108(3), 1039-1053.

Gião, M. S., Gonzalez-Sanjose, M. L., Rivero-Perez, M.D., Pereira, C. I., Pintado, M. E., \& Malcata, F. X. (2007). Infusions of Portuguese medicinal plants: Dependence of final antioxidant capacity and phenol content on extraction features. Journal of the Science of Food and Agriculture, 87(14), 2638-2647.

Gobbo-Neto, L., \& Lopes, N. P. (2008). Online identification of chlorogenic acids, sesquiterpene lactones, and flavonoids in the Brazilian arnica Lychnophora ericoides Mart. (Asteraceae) leaves by HPLC-DAD-MS and HPLC-DAD-MS/MS and a validated
HPLC-DAD method for their simultaneous analysis. Journal of Agricultural and Food Chemistry, 56(4), 1193-1204.

Grayer, Eckert, Lever, A., Veitch, Kite, \& Paton (2010). Distribution of exudate flavonoids in the genus Plectranthus. Biochemical Systematics and Ecology, 38(3), 335-341.

Guvenalp, Z., Ozbek, H., Kuruuzum-Uz, A., Kazaz, C., \& Demirezer, L. O. (2009). Secondary metabolites from Nepeta heliotropifolia. Turkish Journal of Chemistry, 33(5), 667-675.

Horvath, G., Szabo, L. G., Hethelyi, E., \& Lemberkovics, E. (2006). Essential oil composition of three cultivated Thymus chemotypes from Hungary. Journal of Essential Oil Research, 18(3), 315-317.

Justesen, U. (2000). Negative atmospheric pressure chemical ionisation low-energy collision activation mass spectrometry for the characterisation of flavonoids in extracts of fresh herbs. Journal of Chromatography. A, 902(2), 369-379.

Lu, Y., \& Foo, L. Y. (1999). Rosmarinic acid derivatives from Salvia officinalis. Phytochemistry, 51(1), 91-94.

Mata, A. T., Proenca, C., Ferreira, A.R., Serralheiro, M. L. M., Nogueira, J. M. F., \& Araujo, M. E. M. (2007). Antioxidant and antiacetylcholinesterase activities of five plants used as Portuguese food spices. Food Chemistry, 103(3), 778-786.

Miron, T. L., Plaza, M., Bahrim, G., Ibanez, E., \& Herrero, M. (2011). Chemical composition of bioactive pressurized extracts of Romanian aromatic plants. Journal of Chromatography. A, 1218(30), 4918-4927.

Omidbaigi, R., Sefidkon, F., \& Hejazi, M. (2005). Essential oil composition of Thymus citriodorus L. cultivated in Iran. Flavour and Fragrance Journal, 20(2), 237-238.

Ozgen, U., Mavi, A., Terzi, Z., Kazaz, C., Asci, A., Kaya, Y., et al. (2011). Relationship between chemical structure and antioxidant activity of luteolin and its glycosides isolated from Thymus sipyleus subsp sipyleus var. sipyleus. Records of Natural Products, 5(1), 12-21.

Parejo, I., Jauregui, O., Viladomat, F., Bastida, J., \& Codina, C. (2004). Characterization of acylated flavonoid-O-glycosides and methoxylated flavonoids from Tagetes maxima by liquid chromatography coupled to electrospray ionization tandem mass spectrometry. Rapid Communications in Mass Spectrometry, 18(23), 2801-2810.

Pereira, O. R., \& Cardoso, S. M. (2013). Overview on Mentha and Thymus polyphenols. Current Analytical Chemistry, 9(3), 382-396.

Pereira, O. R., Domingues, M. R. M., Silva, A.M. S., \& Cardoso, S. M. (2012). Phenolic constituents of Lamium album: Focus on isoscutellarein derivatives. Food Research International, 48(1), 330-335.

Pereira, O. R., Silva, A.M. S., Domingues, M. R. M., \& Cardoso, S. M. (2012). Identification of phenolic constituents of Cytisus multiflorus. Food Chemistry, 131(2), 652-659.

Pinto, E., Pina-Vaz, C., Salgueiro, L., Goncalves, M. J., Costa-de-Oliveira, S., Cavaleiro, C., et al. (2006). Antifungal activity of the essential oil of Thymus pulegioides on Candida, Aspergillus and dermatophyte species. Journal of Medical Microbiology, 55(10), 1367-1373.

Plazonic, A., Bucar, F., Males, Z., Mornar, A., Nigovic, B., \& Kujundzic, N. (2009). Identification and quantification of flavonoids and phenolic acids in burr parsley (Caucalis platycarpos L.), using high-performance liquid chromatography with diode array detection and electrospray ionization mass spectrometry Molecules, 14(7), 2466-2490.

Reddy, M. V. B., Angers, P., Gosselin, A., \& Arul, J. (1998). Characterization and use of essential oil from Thymus vulgaris against Botrytis cinerea and Rhizopus stolonifer in strawberry fruits. Phytochemistry, 47(8), 1515-1520.

Ribani, M., Bottoli, C. B. G., Collins, C. H., Jardim, I., \& Melo, L. F. C. (2004). Validation for chromatographic and electrophoretic methods. Quimica Nova, 27(5), 771-780.

Snyder, L., Kirkland, J., \& Dolan, J. (2010). Introduction to modern liquid chromatography. New Jersey: John Wiley \& Sons, Inc.

The Herb Society of America (2003). An herb society of america fact sheet: Thyme. Retrieved from. http://www.herbsociety.org/.

Vukics, V., \& Guttman, A. (2008). Structural characterization of flavonoid glycosides by multi-stage mass spectrometry. Mass Spectrometry Reviews, 29(1), 1-16.

Wang, M., Li, J., Ho, G. S., Peng, X., \& Ho, C. T. (1998). Isolation and identification of antioxidative flavonoid glycosides from thyme (Thymus vulgaris L.). Journal of Food Lipids, 5(4), 313-321.

Wijngaard, H., Hossain, M. B., Rai, D. K., \& Brunton, N. (2012). Techniques to extract bioactive compounds from food by-products of plant origin. Food Research International, 46(2), 505-513. 